
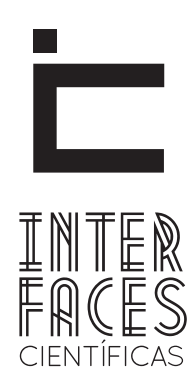

EDUCAÇÃO

ISSN IMPRESSO 2316-333X

E-ISSN 2316-3828

DOI-10.17564/2316-3828.2017v5n3p17-30

\title{
DISCURSOS POLÍTICOS ACERCA DA “IDEOLOGIA DE GÊNERO” NA DISCUSSÃO DO PLANO MUNICIPAL DE EDUCAÇ̃̃O DE JOÃO PESSOA-PB
}

\author{
POLTICAL DISCOURSES ABOUT “THEIDEOLOGY OF GENDER” INTHE DISCUSSION OF THEMUNICIPALEDUCATION PLANOF JOÃOPESSOA/PB/BRAZIL \\ DISCURSOS POLÍTICOS ACERCA DE LA “IDEOLOGÍA DE GÉNERO” EN EL DEBATE DEL PLAN MUNICIPAL DE EDUCACIÓN \\ DE JOÃO PESSOA/PARAÍBA/BRASIL
}

Joel Martins Cavalcante ${ }^{1}$

Maria Eulina Pessoa de Carvalho ${ }^{3}$
Lucas Romário da Silva²

Alfrâncio Ferreira Dias ${ }^{4}$

\section{RESUMO}

Este texto analisa os discursos políticos sobre a chamada "ideologia de gênero" na discussão da proposta do Plano Municipal de Educação (PME) de João Pessoa/PB. A abordagem teórica é influenciada pelos estudos pós-críticos e pós-estruturalistas. A opção metodológica consistiu em abordagem qualitativa dos discursos de quatro vereadores, veiculados nas redes sociais, em um debate televisivo local e durante a sessão de votação do PME na Câmara Municipal, bem como na análise de um panfleto apócrifo intitulado "Você já ouviu falar sobre a 'ideologia de gênero??, distribuído por religiosos/as durante a sessão. Os argumentos utilizados pelos políticos locais - que corroboram posições de políticos federais conservadores, contrários à discussão de gênero e sexualidade na escola, desde o Plano Nacional de Educação (2014) - resultaram na aprovação do PME/JP 2015 suprimindo essa temática. Apenas o eixo de Direitos 
Humanos aprovado no documento engloba genericamente a superação da discriminação por gênero e orientação sexual.

\section{PALAVRAS-CHAVE}

Discursos Políticos. Gênero. Plano Municipal de Educação.

\section{ABSTRACT}

This paper analyses political discourses about the so called "gender ideology" in the discussion of the proposal of the Municipal Education Plan (MEP) of João Pessoa/Paraiba/Brazil. The theoretical approach is influenced by post-critical and poststructuralist studies. The methodological choice consisted of a qualitative approach of the discourses of four city councilors, conveyed in social networks, on a local TV debate, and during the MEP voting session in the City Council, as well as the analysis of a booklet entitled "Have you heard about 'gender ideology'?", distributed by religious agents during the session. The arguments used by local politicians (who support the positions of conservative federal politicians contra- ry to the discussion of gender and sexuality in schools since the approval of the National Education Plan, in 2014), contributed to the omission of the theme within the approved MEP of João Pessoa, in 2015. Only the axis of Human Rights included in the plan accounts for the need to overcome discrimination based on gender and sexuality, albeit in a general manner.

\section{KEYWORDS}

Political Speeches. Gender. Municipal Education Plan.

\section{RESUMEN}

Este texto analiza los discursos políticos sobre la llamada "ideología de género" en el debate de la propuesta del Plan Municipal de Educación (PME) de João Pessoa/Paraíba/Brasil. El enfoque teórico está influenciado por los estudios post-críticos y post-estructuralistas. La opción metodológica consistió en una aproximación cualitativa de los discursos de cuatro concejales, difundidos en las redes sociales, en un debate televisivo local y durante la sesión de votación del PME en de la Cámara Municipal, así como en el análisis de un panfleto apócrifo titulado “¿Ya oyó hablar sobre la 'ideología de género'?”, distribuido por religiosos/as durante la sesión. Los argumentos utilizados por los políticos locales (que corroboran posiciones de políticos federales conservadores, contrarios a la discusión de género y sexualidad en la escuela, desde la aprobación del Plan Nacional de Educación en 2014), resultaron en la aprobación del PME/João Pessoa, en 2015, suprimiendo esa temática. Apenas el eje de Derechos Humanos aprobado en el documento engloba genéricamente la superación de la discriminación por género y orientación sexual.

\section{PALABRAS CLAVE}

Discursos Políticos. Género. Plan Municipal de Educación. 


\section{INTRODUÇão}

Em 2010, ocorreu em Brasília a Conferência Nacional de Educação (CONAE) para pensar a construção do Plano Nacional de Educação e o planejamento da gestão educacional brasileira. No Eixo VI - Justiça Social, Educação e Trabalho: Inclusão, Diversidade e Igualdade, dentre várias propostas para trabalhar com a temática, algumas visam a superar a discriminação por gênero e orientação sexual na escola. De acordo com o documento, a discussão de gênero e diversidade sexual deve fazer parte da política de valorização e formação inicial e continuada dos professores e ser inserida no Programa Nacional do Livro Didático, nos currículos das licenciaturas e da educação básica, dentre outras recomendações. Com base na versão final do documento da CONAE 2010, elaborou-se o Plano Nacional de Educação - PNE 2014-2024, que orienta as atuais políticas educacionais no país. O PNE anterior (2001-2010) não continha qualquer menção ao assunto.

O debate em torno da superação da discriminação por gênero e orientação sexual na discussão do PNE foi muito forte. 0 texto inicialmente aprovado pela Câmara dos Deputados, em 2012, definia que a superação das desigualdades educacionais requeria a "promoção da igualdade racial, regional, de gênero e de orientação sexual". No Senado, que funciona no sistema bicameral como casa revisora, foram suprimidas algumas expressões, e a redação final ficou de modo genérico como "promoção da cidadania e a erradicação de todas as formas de discriminação".

Como houve alteração do texto original, o Projeto de Lei do PNE voltou para a Câmara e lá, novamente, o seu relator, deputado Ângelo Vanhoni (PT-PR), reinseriu o trecho suprimido, gerando uma série de debates. Deputados federais conservadores entendiam que a ênfase na igualdade de gênero e orientação sexual permitiria a adoção de materiais didáticos e atividades escolares que incentivassem a homossexualidade, obrigando as crianças e jovens a naturalizarem aquilo que na concepção deles é antinatural.
O Projeto foi finalmente aprovado com a supressão das formas de discriminação específica. Assim, dentre as diretrizes do PNE, as que tratam da superação da discriminação (inciso III, art. $2^{\circ}$ ) e da promoção da diversidade (inciso $X$, art. $2^{\circ}$ ) ficaram de forma bem genérica. No dia 25 de junho de 2014, a Lei 13.005, que institui o Plano Nacional de Educação, foi sancionada pela Presidente da República, Dilma Rousseff.

No período de 19 a 23 de novembro de 2014, portanto, após a aprovação e sanção do PNE, ocorreu a II CO$\mathrm{NAE}$, que indicou que o planejamento e as políticas no Brasil devem orientar-se, dentre outras diretrizes, pela superação das desigualdades educacionais, com ênfase na promoção da igualdade racial, regional, de gênero e de orientação sexual, e na garantia de acessibilidade. Assim, o Eixo II - Educação e Diversidade: Justiça Social, Inclusão e Direitos Humanos coloca "o respeito à efetivação da educação pública democrática, popular, laica e com qualidade social, banindo o proselitismo, o racismo, o machismo, o sexismo, a homofobia, a lesbofobia e a transfobia nas instituições educativas de todos os níveis, etapas e modalidades" (MINISTÉRIO DA EDUCAÇÃO, 2014, p. 29) como eixo central da educação e objeto da política educacional. Nesse sentido, são várias as proposições e estratégias contidas no documento.

De acordo com o PNE (art. $8^{\circ}$ da Lei 13.005), os Estados, o Distrito Federal e os Municípios teriam até 24 de junho de 2015 para sancionar seus respectivos planos estaduais, distritais e municipais de educação. Como o Plano Nacional serve de norte, e seguindo as orientações da II CONAE, os projetos dos planos traziam diretrizes e metas para combater a discriminação por gênero e orientação sexual. Novamente, discussões e debates vieram à tona. Certos grupos religiosos e conservadores construíram todo um arsenal discursivo no sentido de combater a chamada "ideologia de gênero" presente nos planos. Na capital da Paraíba, João Pessoa, essa realidade não foi diferente.

Por "ideologia de gênero" grupos conservadores, principalmente fundamentalistas religiosos cristãos, en- 
tendem o discurso científico que conceitua gênero como uma construção histórica, social e cultural da identidade individual e social (construção essa distinta de sexo e orientação sexual), bem como da ordem social e simbólica (androcêntrica) - em contraposição a sua crença de que o gênero seria um dado da natureza, uma determinação biológica, ou uma criação divina. Assim, pretendem que a ideologia do "gênero natural", binário, associado à heteronormatividade, passe por verdade, e o conceito de gênero como construção cultural passe por ideologia.

Para Scott (1995, p. 86), “o gênero é um elemento constitutivo de relações sociais fundadas sobre as diferenças percebidas entre os sexos, e o gênero é um primeiro modo de dar significado às relações de poder". Sendo todas as relações sociais permeadas por poder (FOUCAULT, 1999), a relação entre os sexos tem sido de dominação masculina (BOURDIEU, 1999), colocando a mulher (e outros a ela equiparados) em situação de desvantagem social e vítima de processos de violência simbólica, institucional e física.

A teorização sobre as relações de gênero no âmbito dos estudos de mulheres e feministas criou um novo campo científico a partir da segunda onda do feminismo (dos anos de 1960 em diante). Porém o conceito de gênero é complexo e de difícil sensocomunização (CARVALHO, 2010), pela associação da noção de gênero à perspectiva religiosa criacionista. Assim, no senso comum (e mesmo na academia) gênero aparece frequentemente como sinônimo de sexo (CARVALHO; RABAY, 2015), ambos restritos ao binarismo.

Partindo dessas considerações, este texto busca articular questões epistemológicas presentes nos estudos sobre gênero e sexualidades com reflexões sobre os discursos de políticos locais, veiculados na mídia, contra a referida "ideologia de gênero", no contexto da discussão do Plano Municipal de Educação de João Pessoa (PB), aprovado em 2015.

A opção metodológica recaiu sobre a abordagem qualitativa (DENZIN, 2006) dos discursos de quatro vereadores do município de João Pessoa, veiculados nas redes sociais, em um debate televisivo local e durante a sessão de votação do PME na Câmara Municipal, sobre a inclusão da "ideologia de gênero" no plano, bem como um panfleto apócrifo, distribuído por religiosos/as, intitulado Você já ouviu falar sobre a "ideologia de gênero"? Conheça esta ideologia e entenda o perigo que você e seus filhos estão correndo! As análises são influenciadas pelos estudos pós-críticos, em que o "mapa do poder é ampliado para incluir os processos de dominação centrados na raça, na etnia, no gênero e na sexualidade" (SILVA, 2011, p. 149), bem como pelos estudos pós-estruturalistas, a partir da perspectiva de que a linguagem e os processos de significação influenciam a produção das relações sociais e do conhecimento.

\section{GÊNERO E SEXUALIDADE NO CURRÍCULO ESCOLAR}

Dentre as diversas questões que transitam nos cenários sociais e políticos, a de gênero e orientação sexual tem despontado de forma polêmica nos últimos tempos. Sua inclusão nos currículos escolares, através dos planos nacional, estaduais e municipais, tem suscitado debates e embates a favor dos direitos humanos das mulheres e das pessoas lésbicas, gays, bissexuais, travestis e transexuais (LGBT) e contra a denominada "ideologia de gênero". Os que são favoráveis à inclusão das questões de gênero e sexualidade na escola reconhecem as desigualdades, injustiças e exclusões históricas que afetaram e ainda afetam esses grupos fora e, sobretudo, dentro dela.

Diferenças, distinções, desigualdades... A escola entende disso. Na verdade, a escola produz isso. Desde seus inícios, a instituição escolar exerceu uma ação distintiva. Ela se incumbiu de separar os sujeitos - tornando aqueles que nela entravam distintos dos outros, os que a ela não tinham acesso. Ela dividiu também, internamente, os que lá estavam, através de múltiplos mecanismos de classificação, ordenamento, hierarquização. A escola que nos foi legada pela sociedade ocidental moderna começou por separar adultos de crianças, católicos de protestantes. Ela também se fez diferente para os ricos e para os pobres e ela imediatamente separou os meninos das meninas (LOURO, 2007, p. 57).

Para acolher os/as diferentes, respeitando as singularidades humanas, e promover a convivência amis- 
tosa na diversidade, é preciso denunciar, compreender a gênese e desconstruir as polarizações e dicotomias, assimetrias e hierarquias sociais (rico/pobre, branco/ negro, normal/anormal, heterossexual/homossexual, masculino/feminino) no currículo escolar, entendido em suas várias dimensões (formal, oculto e em ação).

O currículo é um espaço de embates de políticas culturais, portanto, é vinculado às relações de poder, não apenas no plano estatal, mas espalhadas em toda a rede social, que inclui em seu mapa os processos de dominação centrados na raça, etnia, classe, no gênero e na sexualidade (SILVA, 2011). As questões do corpo, gênero e sexualidade, silenciadas ou normatizadas na prática pedagógica, aparecem de modo imprevisto na sala de aula (DIAS, 2015a; SEFFNER, 2011; DORNELLES; POCAHY, 2014; PINTO, 2011). Tendo em vista que o currículo escolar não é neutro e que as questões de gênero e sexualidade estão nele presentes, implícita e explicitamente, as políticas e práticas curriculares podem reforçar ou questionar as desigualdades, normatizações, estereótipos, preconceitos e discriminações concernentes à sexualidade e ao gênero (DIAS, 2014b). Todavia, a escola tem sido conservadora:

\footnotetext{
Uma noção singular de gênero e sexualidade vem sustentando currículos e práticas de nossas escolas. Mesmo que se admita que existem muitas formas de viver os gêneros e a sexualidade, é consenso que a instituição escolar tem obrigação de nortear suas ações por um padrão: haveria apenas um modo adequado, legítimo, normal de masculinidade e de feminilidade e uma única forma sadia e normal de sexualidade, a heterossexualidade; afastar-se desse padrão significa buscar o desvio, sair do centro, tornar-se excêntrico (LOURO, 2003, p. 43-44).
}

A heteronormatividade implica polaridade de sexo e gênero, assim masculinidade e feminilidade demarcam os corpos, os lugares e papéis de homens e mulheres. Todos os bens produzidos pela sociedade, sejam eles materiais ou simbólicos, são destinados a quem vive segundo seus preceitos, excluindo-se os que nela não se enquadram ou os que estão na fronteira (MISKOLCI, 2009; DIAS; OLIVEIRA, 2015). Dessa forma, os/as que não são heterossexuais estão passíveis de incorrer em punições, privações e discriminações, no contexto da homofobia. De acordo com Borrillo (2010, p. 34),
A homofobia pode ser definida como a hostilidade geral, psicológica e social contra aqueles e aquelas que, supostamente, sentem desejo ou têm práticas sexuais com indivíduos de seu próprio sexo. Forma específica de sexismo, a homofobia rejeita, igualmente, todos aqueles que não se conformam com o papel predeterminado para seu sexo biológico. Construção ideológica que consiste na promoção constante de uma forma de sexualidade (hetero) em detrimento de outra (homo), a homofobia organiza uma hierarquização das sexualidades e, dessa prática, extrai consequências políticas.

Em relação à orientação sexual e à articulação com gênero, é importante destacar que não apenas gays, lésbicas, travestis e transexuais são vítimas de homo/ lesbo/transfobia. Heterossexuais também sofrem quando não estão no papel que culturalmente é reservado ao seu gênero. Como diz Louro (2010, p. 28), a "homofobia funciona como mais um importante obstáculo à expressão de intimidade entre homens, além disso, ela funciona "como uma espécie de vigilância do gênero" (BORRILLO, 2010, p. 26). 0 gênero, portanto, é como um filtro por meio do qual as pessoas são avaliadas e têm acesso a mais ou menos direitos e/ou privilégios.

Sob um discurso curricular sexista/machista, heterossexista/homofóbico, padronizador e homogeneizador, meninas e meninos têm tido suas diversas formas de masculinidade e feminilidade apagadas ou rechaçadas pela escola. Segundo Silva (2011), professoras/es, mesmo que inconscientemente, têm expectativas diferentes para meninas e meninos e tentam enquadrá-las/ los no que seria "correto" para seu corpo/sexo/gênero (DIAS, 2014a). Assim, o currículo escolar disciplina os corpos e condiciona as mentes, por exemplo, define as matérias e aptidões de meninas e meninos, determinando suas escolhas ocupacionais (SILVA, 2011).

A discriminação e o preconceito contra estudantes LGBT é muito comum na escola. A maioria dos sujeitos que fogem ao padrão considerado normal de gênero e sexualidade já passou por bullying no espaço escolar, por não representarem modelos de masculinidade e feminilidade desejável ou aceitável, pautados nas imagens de homem/ mulher, branco/branca, cristão/cristã e heterossexual.

A solução para as desigualdades em razão do gênero e da sexualidade não seria uma inversão, ou seja, 
supervalorizar a mulher ou as pessoas LGBT em detrimento do homem heterossexual, como apregoam capciosamente os grupos reacionários, mas buscar a equidade entre os diferentes gêneros e sexualidades. Silva (2011, p. 94) afirma que "a solução não consistiria simplesmente numa inversão, mas em construir currículos que refletissem de forma equilibrada, tanto a experiência masculina quanto a feminina" e reconhecessem as várias possibilidades de vivência da sexualidade.

O discurso de que "para eles" (intelectuais e militantes feministas e LGBT) "não existe "homem ou mulher', é cada um que deve inventar sua própria personalidade, como quiser", aparece em um panfleto distribuído na Câmara Municipal de João Pessoa, no dia da votação do Plano Municipal de Educação, o qual também suprimiu qualquer menção explícita às questões de gênero e sexualidade no seu texto.

A seguir, o panfleto intitulado Você já ouviu falar sobre a "Ideologia de gênero"? Conheça esta ideologia e entenda o perigo que você e seus filhos estão correndo! será analisado, bem como alguns discursos de vereadores de João Pessoa.

\section{PLANO MUNICIPAL DE EDUCAÇÃO DE JOÃO PESSOA: DISCURSOS SOBRE A "IDEOLOGIA DE GÊNERO"}

O Plano Municipal de Educação de João Pessoa foi aprovado no dia 17 de junho de 2015, um dia antes da data prevista. No momento em que foi posto em votação, um vereador registrou em sua fala que não tinha ocorrido nenhuma discussão e/ou leitura prévia do PME, por isso se absteve de votar. Em protesto, publicou em sua página no Facebook ${ }^{1}$, a sua indignação:

Avisar a tod@s os educadores que de forma extraordinariamente esquisita o Plano Municipal de Educação

\footnotetext{
1. Rede social fechada para membros. A rede faculta aos seus usuários optarem pela privacidade, compartilhando suas publicações somente com os amigos, ou podem deixar abertas ao público, como foi o caso dos depoimentos aqui apresentados.
}

foi aprovado sem debate nenhum em 37 segundos. Repito, sem nenhuma fala. Exceto a minha de protesto. Após a "votação" pedi para registrar minha abstenção. Não li o plano (acho q ninguém leu) a sociedade civil, educadores e câmara ficou pequena neste "modus operandi" que o poder executivo operou na câmara. Junto com ela a democracia esvai-se sem resultados e sem funcionalidade. \#diavergonhoso, \#ofuturo há de julgar dias como esse. (MARTINS, 2015).

Se o Plano Municipal de Educação foi aprovado sem uma leitura ou discussão prévia como um todo, um ponto em particular gerou uma discussão que movimentou as redes sociais e fez com que a Câmara Municipal de João Pessoa, no dia 17 de junho de 2015, ficasse lotada: a inclusão das discussões referentes a gênero e orientação sexual no PME.

$\mathrm{Na}$ rede social Facebook, outro vereador postou um vídeo no dia anterior, falando que o prefeito da cidade tinha incluído a "ideologia de gênero" no PME, contrariando a decisão do Congresso Nacional acerca do PNE. Em sua publicação, ele afirma: "tenho certeza que os vereadores cristãos não aprovarão essa medida" (MENDES, 2015b). Em debate em uma emissora de televisão local, logo após a aprovação do PME, ele ressaltou que o Plano foi aprovado porque o Presidente da Câmara não aceitou qualquer referência à palavra gênero, além de afirmar que houve pressão de vários atores no sentido de retirar essa discussão do PME. "Nós não poderíamos ter a opção de ensinar a crianças de quatro, cinco anos que ela não teria a sua sexualidade definida" (MENDES, 2015a).

No mesmo debate, o vereador Marco Antônio Souza, que se afirma como católico, ressaltou que houve uma pressão dos setores religiosos (SOUZA, M. A., 2015). Um quarto vereador escreveu um texto em sua página pública no Facebook em que se posiciona contrário à "ideologia de gênero". Segundo ele,

A ideologia de gênero afirma que ninguém nasce homem ou mulher, mas deve construir a sua identidade, isto é, o seu gênero, ao longo da vida. [...] De acordo com essa ideologia, gênero seria uma construção individual, de modo que ninguém seria identificado como homem ou mulher, mas cada um deveria criar a sua própria identidade. Nesse compasso, nossas crianças 
aprenderiam que não seriam meninos ou meninas, mas que deveriam, em seus cotidianos, criarem a sua própria identidade. Para isso, receberiam materiais didáticos destinados a difundir essa e outras temáticas, como, por exemplo, a sexualidade. (FARIAS, 2015).

0 vereador destaca ainda que alguns dos partidários da "ideologia de gênero" são contrários às celebrações como "Dia dos Pais", "Dia das Mães", para que houvesse apenas o "Dia da Família". Ademais, segundo ele, "essa questão de gênero chega a ser tão radical que muitos são contra até a divisão de banheiros em masculino e feminino" (FARIAS, 2015). Ele vê a escola como "templo do conhecimento e da cidadania".

Na escola, o principal é a difusão do saber (Português, Matemática, Ciências, História, Geografia, Língua Estrangeira, etc...) e a transmissão de valores fundamentais de cidadania como respeito ao próximo, a preservação do meio ambiente, fazer a coleta seletiva, obedecer as regras de trânsito, ser contra qualquer tipo de preconceito, cultivar princípios morais como respeitar os pais e professores, não roubar, não praticar bullying, não agredir as pessoas, enfim, a escola é um espaço essencial na construção da personalidade e do caráter de nossos cidadãos. (FARIAS, 2015).

0 vereador coloca ainda que, como cristão, compreende a necessidade do respeito e da tolerância para a harmonia da sociedade, que defende a regulamentação de direitos dos homossexuais, mas é contrário à implantação da ideologia de gênero na escola. Apesar de se mostrar a favor dos direitos dos homossexuais, não podemos deixar de identificar que há um discurso velado em sua fala, uma vez que, ao se manifestar contrário às discussões de gênero e sexualidade na escola, está privando os alunos e as alunas de terem acesso ao conhecimento sobre a temática e, consequentemente, propiciando a continuidade da ignorância acerca do assunto, o que gera processos discriminatórios, preconceituosos e produção de estereótipos. A escola precisa romper com essa visão estreita acerca de gênero e sexualidade e ampliar os debates para que venha à tona a noção da pluralidade que inclui os diferentes.
Para além de uma compreensão estereotípica, rígi$\mathrm{da}$, hierarquizante, disciplinar, normalizadora da diversidade cultural, emerge o campo híbrido, fluido, polissêmico, ao mesmo tempo trágico e promissor da diferença, que se constitui nos entrelugares e nos entreolhares das enunciações de diferentes sujeitos e identidades socioculturais. (FLEURI, 2006, p. 512).

No dia da votação, grupos de evangélicos e católicos estavam na Câmara e distribuíam um panfleto com o título Você já ouviu falar sobre a "Ideologia de Gênero"? Conheça esta ideologia e entenda o perigo que você e seus filhos estão correndo. Além de incluir várias questões proferidas pelos vereadores, o panfleto afirma que "querem destruir nossas famílias" e conclama as pessoas a procurarem as câmaras municipais e assembleias legislativas e conversarem com os vereadores e deputados estaduais para que isso não seja implantado. Em seu conteúdo, traz o panfleto:

\footnotetext{
Talvez você tenha visto na televisão alguém dizer que a família é uma instituição antiquada, e que os tempos mudaram, que precisamos "abrir a cabeça"? Existem organizações muito ocupadas em destruir nossas famílias. Dizem que o povo é muito fora de moda e que precisamos deixar os ensinamentos dos antigos e nos abrirmos às novidades. E que novidades! Como não estão conseguindo mudar a cabeça da população, inventam novos recursos para nos sabotarem. $\mathbf{0}$ mais disfarçado e perigoso é a "Ideologia de Gênero". (Panfleto apócrifo, 2015, p. 4, grifos no original).
}

Há no conteúdo desse panfleto uma nítida distorção das ideias, valores e princípios que pregam os estudos feministas e de sexualidade, os movimentos sociais e intelectuais adeptos desses estudos, pois seus princípios buscam a inclusão de diferentes núcleos familiares existentes na contemporaneidade, e a supressão das ações discriminatórias e preconceituosas no contexto escolar.

Para um dos vereadores, a discussão de gênero e sexualidade não deve ser prioridade na escola, o que deve ser ensinado são os valores morais presentes na família. Segundo ele,

Definir padrões morais de forma impositiva, como se pretende através da legalização da ideologia de gênero, simplesmente não funciona. 0 que deve ser feito, e de 
forma inteligente, é ensinar às crianças que uma família é composta por valores. A sexualidade não é o sentido maior da família. Não é necessário formar uma família para se ter um filho, mas a mesma não se mantém, seja ela de que tipo for, sem que os valores éticos fundamentais estejam em primeiro lugar. (FARIAS, 2015).

Indagamos: ao desconsiderar as discussões de gênero e sexualidade na escola, não estaríamos negando o valor ético-moral das diferentes famílias, compostas por pessoas de gêneros e sexualidades que fogem do tradicional? Como diz o vereador, nenhuma família se mantém sem os valores éticos fundamentais, porém ele não explicita que valores são esses e qual o seu alcance. Acreditamos que dificilmente é possível ensinar às crianças valores como amor, lealdade, solidariedade, fraternidade, igualdade, respeito e união sem que essas conheçam e respeitem, à luz dos princípios da alteridade e da ética, as diferentes famílias.

Destacamos dois pontos comuns nos discursos dos vereadores e no panfleto distribuído na Câmara Municipal de João Pessoa. 0 primeiro ponto é a perspectiva religiosa permeando todo o debate, visto que os/as vereadores/as são católicos/as ou evangélicos/as e fazem questão de frisar isso durante as discussões. Nesse ponto, o cenário de João Pessoa é um reflexo do cenário nacional. No Congresso Nacional, por exemplo, existe uma bancada evangélica forte e que atua no sentido de impor seus interesses religiosos aos demais cidadãos. Apesar de, doutrinariamente, evangélicos e católicos serem separados, nos últimos tempos existe uma aliança política entre eles, sobretudo para barrar qualquer situação contrária à família tradicional (formada apenas por casal de sexos opostos) e à moral cristã.

0 segundo ponto refere-se à limitação da concepção de currículo escolar. 0 currículo, na visão defendida pelos vereadores, seria limitado a conteúdos das disciplinas tradicionais, mais algumas noções de cidadania e respeito, sem, em hipótese alguma, poder se referir ou discutir questões relativas a gênero e sexualidade. Os discursos curriculares e as práticas pedagógicas tentam constantemente apagar as diferenças e homogeneizar as identidades na escola. Sendo uma instituição conservadora, a escola tende a negar o novo cenário cultural emergente que rompe com as concepções e valores tradicionalmente cultivados. Ela não está preparada para lidar com as múltiplas identidades, afinal "trata-se do desafio de se respeitar as diferenças e de integrá-las em uma unidade que não as anule, mas que ative o potencial criativo e vital da conexão entre diferentes agentes e entre seus respectivos contextos" (FLEURI, 2006, p. 497).

Seria possível não incluir gênero e sexualidade no currículo escolar e fazer da escola "templo do conhecimento e da cidadania" e disseminadora de "valores éticos fundamentais"? Dificilmente, pois, mais uma vez a escola estaria produzindo processos excludentes, discriminatórios e ofuscantes das diferentes identidades nela presentes. Ademais, a legislação brasileira veda expressamente qualquer forma de discriminação.

Segundo a Constituição Federal de 1988 (art. 30, IV), um dos objetivos fundamentais da República é "promover o bem de todos, sem preconceitos de origem, raça, sexo, cor, idade e quaisquer outras formas de discriminação" (BRASIL, 1988/2011). No que se refere à educação, a Lei Maior coloca no caput do art. 205 que "a educação, direito de todos e dever do Estado e da família, será promovida e incentivada com a colaboração da sociedade, visando ao pleno desenvolvimento da pessoa, seu preparo para o exercício da cidadania e sua qualificação para o trabalho" (BRASIL, 1988/2011).

A Lei de Diretrizes e Bases da Educação Nacional (Lei 9.394 de 1996), em consonância com o texto constitucional, ressalta no Art. $3^{\circ}$ que

Art. $3^{0}$ - 0 ensino será ministrado com base nos seguintes princípios:

I - igualdade de condições para o acesso e permanência na escola;

[...]

III - pluralismo de ideias e de concepções pedagógicas; IV - respeito à liberdade e apreço à tolerância.

[...] (BRASIL, 1996/2008).

Percebe-se, portanto, que as duas normas que são referências seminais para a educação nacional pregam, como um dos objetivos da educação, a formação plena do indivíduo para exercer a cidadania. Isso 
implica o respeito à liberdade e o apreço à tolerância, por isso o ensino deve ser plural, fato que respalda as discussões a respeito das questões de gênero e sexualidade na escola. Além disso, a Constituição veda expressamente qualquer forma de discriminação, abarcando, portanto, a homofobia, lesbofobia e transfobia.

O texto final do Plano Municipal de Educação de João Pessoa (Lei Municipal 13.035 de 19 de Junho de 2015) coloca em seu Art. $3^{\circ}$ que as diretrizes para o período de 2015 a 2025 dentre outras, são:

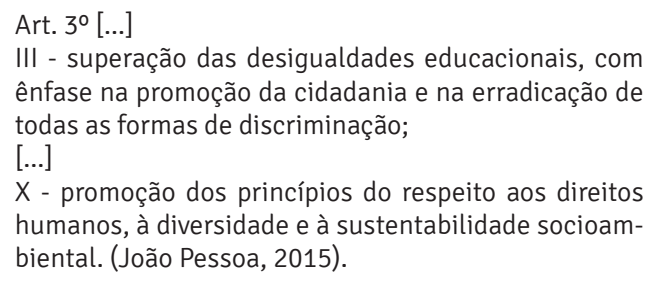

$X$ - promoção dos princípios do respeito aos direitos humanos, à diversidade e à sustentabilidade socioambiental. (João Pessoa, 2015).

0 diagnóstico do eixo 12, que trata da valorização da diversidade, ressalta que "a escola é um dos principais agentes responsáveis tanto por manter e alimentar como também criar novas estratégias inclusivas no combate às discriminações por raça, gênero, etnia, renda, orientação sexual, diferenças físicas e deficiências, entre outras". A Meta 20 fala em implementar a Educação em Direitos Humanos em todos os níveis, etapas e modalidades de ensino, contemplando a inclusão de práticas pedagógicas, a confecção de materiais didáticos, formação de professores, pesquisas, dentre outras estratégias, para a criação de uma cultura de paz, de respeito às diferenças e valorização dos direitos humanos.

Nesse cenário, não obstante toda a pressão para a exclusão dos termos orientação sexual e identidade de gênero das metas e estratégias do PME, o texto aprovado pela Câmara Municipal não proíbe (nem poderia proibir) que essa temática seja debatida e que haja políticas para a valorização da diversidade. Pelo contrário, apesar de não estar explicitamente na Lei, o município tem o dever legal de implementar ações para combater as discriminações e preconceitos no âmbito escolar.

\section{CONSIDERAÇÕES FINAIS}

Os discursos sobre as questões de gênero e sexualidade são relativamente recentes, sobretudo no campo educacional. Entretanto, percebemos que os estudos e teorias acerca do assunto avançaram consideravelmente, transcendendo as concepções naturais/essencialistas e religiosas/criacionistas em direção às culturais.

Apesar do significativo avanço, é difícil a sensocomunização do conceito de gênero, em sua multidimensionalidade e complexidade, principalmente pela sua associação às perspectivas biológica/positivista e religiosa, as quais configuram posições ideológicas e políticas que reforçam visões binárias e dicotômicas, negando a diversidade sexual e de gênero.

Nesse contexto, educadores/as, intelectuais e ativistas políticos/as, preocupados/as com a discriminação, preconceitos e violências relacionados a gênero e sexualidade, têm buscado inserir, em documentos legais e de políticas públicas, garantias de direitos e de respeito às diferenças, como ocorreu durante a CONAE em 2014.

Todavia, quando documentos como os planos de educação chegam ao Poder Legislativo esbarram em discursos conservadores e contrários a uma sociedade menos assimétrica, desigual, excludente e desumana. Isso ocorreu no Plano Nacional de Educação, no Plano Estadual de Educação da Paraíba e no Plano Municipal de Educação de João Pessoa.

Em nível municipal, vereadores de João Pessoa vetaram a inserção das questões de gênero e sexualidade no PME com base no discurso capcioso contrário a uma suposta "ideologia de gênero", veiculado nacionalmente. Segundo eles, repetindo esse discurso, com a inclusão da temática de gênero na formação inicial e continuada de professores e nos currículos escolares, algumas “organizações” estariam tentando destruir a família e propiciando que as crianças apreendessem que não seriam meninos ou meninas, entre outras afirmações alarmistas.

Com base nas concepções naturalista e religiosa, os discursos dos políticos de João Pessoa não respeitam as diferentes e múltiplas identidades que se en- 
contram na escola. Entretanto, sabemos que as discussões e a luta política acerca do fortalecimento da temática no contexto educacional não podem cessar.

Desse modo, embora o PME de João Pessoa não inclua uma discussão específica acerca da temática de gênero e sexualidade, professores/as da rede municipal de educação não estão proibidos de trabalhar o assunto na escola, pois o eixo de Direitos Humanos aprovado no documento engloba genericamente a superação da discriminação por gênero e orientação sexual.

Longe do que seria o ideal, na tentativa de driblar esses discursos opressores e conservadores, educadores/ as pessoenses devem buscar no seu cotidiano, através de suas práticas pedagógicas e curriculares, a superação das discriminações, preconceitos, estigmas, violências e exclusão social para com as meninas e meninos que não se enquadrem na heteronormatividade e nos papéis e identidades de gênero binárias tradicionais.

Para finalizar registramos o exemplo do professor Marcos Lopes de Souza² que, ao perceber a veiculação de uma carta aberta à comunidade do município de Jequié (BA) para o enfrentamento da "Ideologia de Gênero" no PME, revolveu se pronunciar, expondo argumentos contrários aos da carta distribuída por religiosos em diversas cidades brasileiras.

Diante da carta encaminhada pelo bispo de Jequié em relação a uma suposta "ideologia” de gênero que estaria presente no Plano Municipal de Educação (PME), vimos nos posicionar argumentando favoravelmente à permanência das questões de gênero e também de orientação sexual nos propósitos do PME. Primeiramente, afirmamos que não existe "ideologia", conforme mencionado, já que não se deseja impor pensamentos, "conscientizar" as pessoas ou muito menos normatizar ou uniformizar os estudantes, já que prezamos pelo respeito às diversidades.

Pretendemos com as discussões sobre gênero na escola reconhecer a existência de uma história brasileira marcada pela marginalização e desigualdade de gênero, em especial, em relação às mulheres que mesmo com suas conquistas ainda têm sido desvalorizadas, sobretudo quanto à remuneração salarial, ocupação profissional

2 Professor da Universidade Estadual do Sudoeste da Bahia (UESB), líder do Grupo de Estudos e Pesquisas em Gênero e Sexualidades (CNPq). ou participação na representação política, e inferiorizadas por meio dos feminicídios, fazendo do Brasil o sétimo país do mundo com as maiores taxas de violência contra as mulheres conforme dados disponíveis no site da Organização das Nações Unidas (ONU), inclusive só em 2012 foram registrados 50.000 estupros no Brasil. A ONU também tem realizado uma campanha "Livres \& Iguais" a fim de promover o combate à violência e à discriminação contra lésbicas, gays, bissexuais, travestis e transexuais (LGBT) no mundo, incluindo o Brasil.

[...] Também reiteramos que o Plano Municipal de Educação (PME) não almeja desconstruir a família, a maternidade ou o matrimônio como exposto na carta, ao contrário, defendemos que todas as pessoas, e repetimos todas as pessoas, indistintamente, tenham o direito de escother o caminho que desejam para suas vidas, inclusive o de construir famílias, serem mães ou pais e se casarem. Da mesma forma entendemos que devem ser considerados e respeitados os "outros" arranjos familiares que vêm se produzindo há algum tempo, pois assim estaremos, de fato, construindo uma sociedade justa, livre e solidária como já defendido pela Constituição de 1988.

Com base nas legislações, documentos educacionais oficiais e pesquisas realizadas por universidades e instituições nacionais e internacionais reconhecemos a importância de se valorizarem as diferenças e defendemos que a escola brasileira e, por conseguinte, jequieense não se silencie frente ao sexismo (discriminação de sexo/gênero), à misoginia (rejeição às mulheres e à feminilidade) e à lesbo-homo-bi-transfobia (manifestação de rejeição e ódio aos(às) lésbicas, gays, bissexuais e transgêneros). Isto não significa que devamos "impor" às pessoas que "se tornem" homossexuais como temos ouvido por parte de pessoas desinformadas e equivocadas. Contrariamente, defendemos o respeito a todas as identidades de gênero e orientações sexuais e, obviamente, também o respeito às pessoas heterossexuais. Inclusive a violência de gênero e sexual tem se intensificado de tal forma que os heterossexuais têm sido vítimas dela: são irmãos, pais e filhos e amigos que foram violentados por terem sido confundidos com casais homossexuais.

Finalizamos reafirmando que o papel da escola, defendido pelo PME e também por nós, intenta contribuir para a formação de crianças, adolescentes, jovens e adultos que reconheçam a importância do respeito às pluralidades sejam elas de origem social, cultural, étnico-racial, de gênero, orientação sexual, religiosa, de nacionalidade, condição física, sensorial e socioemocional, geracional, entre outras e, com isso auxiliaremos na construção de uma sociedade menos injusta, menos violenta, menos desumana e mais respeitosa, amorosa e pacífica. (SOUZA, M. L., 2015, p. 1-3). 


\section{REFERÊNCIAS}

BRASIL. Constituição da República Federativa do

Brasil - 1988. Brasília: Senado Federal, 2011.

BRASIL. Lei nº 9.394 de 20 de Dezembro de 1996. Lei de Diretrizes e Bases da Educação Nacional. Brasília: Senado Federal, 2008.

BRASIL. Lei no 13.005 de 25 de junho de 2014. Aprova o PNE e dá outras providências. Disponível em: http://www.planalto.gov.br/CCIVIL_03/_Ato20112014/2014/Lei/L13005.htm. Acesso em: 10 jul. 2015.

JOÃO PESSOA. Lei Ordinária n⿳0 13.035, 19 de Junho de 2015. Dispõe sobre o Plano Municipal de Educação 2015-2025 e dá outras providências. Disponível em: http://www.joaopessoa.pb.gov.br/ portal/wp-content/uploads/2015/06/2015_1481. pdf?4028d8. Acesso em: 10 jul. 2015.

BORRILLO, D. Homofobia: história e crítica de um preconceito. Tradução de Guilherme João de Freitas Teixeira. Belo Horizonte: Autêntica, 2010.

BOURDIEU, P. A dominação masculina. Rio de Janeiro: Bertrand Brasil, 1999.

CARVALHO, M. E. P. de. Gênero é um conceito complexo e de difícil sensocomunização: considerações a partir de uma experiência de formação docente. Revista Instrumento, Juiz de Fora v. 12, n. 2, p. 75-87, jul./dez. 2010.

CARVALHO, M. E. P.; RABAY, G. Usos e incompreensões do conceito de gênero no discurso educacional no Brasil. Estudos Feministas, Florianópolis, v. 23, n. 1, p. 119-136, jan./abril. 2015.

DENZIN, N. K. 0 planejamento da pesquisa qualitativa: teorias e abordagens. Porto Alegre: Artmed, 2006.
DIAS, A. F. Como as escolas educam corpos nas práticas pedagógicas? Revista Tempos e Espaços em Educação. São Cristóvão (SE), v. 7, n. 12, p. 103-112, jan./abril 2014a.

\section{DIAS, A. F.. Formação de professores para uma} educação não discriminadora. Aracaju, Infografhics, 2014b.

DIAS, A. F.; OLIVEIRA, D. A. As abordagens de corpo, gênero e sexualidades no Projeto Político Pedagógico em um Colégio Estadual de Aracaju, SE. HOLOS, Natal, v. 3, p. 259-271, jul. 2015.

DORNELLES, P. G.; POCAHY, F. A. "Prendam suas bezerras que o meu garrote está solto!" Interseccionando gênero, sexualidade e lugar nos modos de subjetivação regionais. Educar em Revista, Curitiba, Edição Especial n. 1, p. 117-133, jan. 2014.

FARIAS, B. Página pessoal. In Facebook. Publicada em 17 de julho de 2015. Disponível em: <https:// www.facebook.com/brunofariasdepaiva/posts/7 $56890677742825>$. Acesso em: 29 jul. 2015.

FLEURI, R. M. Políticas da diferença: para além dos estereótipos na prática educacional. Educação e Sociedade [online], Campinas, vol. 27, n. 95, p. 495520, mai/ago. 2006.

FOUCAULT, M. Microfísica do poder. Tradução de Roberto Machado. 14. ed. Rio de Janeiro: Graal, 1999.

LOURO, G. L. Currículo, gênero e sexualidade - 0 “normal”, o “diferente" e o "excêntrico". In: LOURO, G. L.; NECKEL, J. F.; GOELLNER, S. V. (Orgs.). Gênero e Sexualidade: um debate contemporâneo na educação - Petrópolis, RJ: Vozes, 2003.

LOURO, G. L. Gênero, sexualidade e educação: uma perspectiva pós-estruturalista. Petrópolis, RJ: Vozes, 2007. 
LOURO, G. L. Sexualidades minoritárias e educação: novas políticas? In: POCAHY, F. Políticas de enfrentamento ao heterossexismo: corpo e prazer. Porto Alegre: Nuances, 2010.

MARTINS, R. Página pessoal. In: Facebook. Publicada em 17 de julho de 2015. Disponível em: <https://www.facebook.com/AmigosRenato/ posts $/ 852877991466483$ ? pnref=story $>$. Acesso em 29 jul. 2015.

MENDES, R. Vídeo. Página de Raoni Mendes aberta ao público. In: Facebook. Publicado em 16 de julho de 2015a. Disponível em: <https://www.facebook. com/raonibmendes /videos/vb. 570693256352787/ 839595489462561/?type=2\&theater $>$. Acesso em 29 jul. 2015.

MENDES, R. Entrevista ao Programa Correio em Debate em 30 de junho de 2015b. TV

Correio João Pessoa. Disponível em: <https:// www.facebook.com/raonibmendes/videos/vb. 570693256352787/845934182162025/?type=2\&the ater.> Acesso em: 30 jul. 2015.

\section{MINISTÉRIO DA EDUCAÇÃO. Documento Base da}

CONAE 2014. Documento Base. Volume I e II, 2014. Disponível em: <http://conae.mec.gov.br/index.php? option=com_content\&view=article\&id $=327$ : docume nto-base-\&catid=38: documentos\&ltemid=59>. Acesso em: 30 jul. 2015.

MISKOLCI, R. A Teoria Queer e a Sociologia: o desafio de uma analítica da normalização. Sociologias, Porto Alegre, ano 11, n. 21, p. 150-182, jan./jun. 2009.
PINTO, J. P. Ler e escrever sobre corpos: metodologia feminista para letramento de jovens. Cadernos de Pesquisa, São Paulo, v. 41, n. 143, p. 538-558, mai/ ago. 2011.

SCOTT, J. W. Gênero: uma categoria útil de análise histórica. Educação e Realidade, Porto Alegre, vol. 20, n. 2, (2), jul/dez. 1995.

SEFFNER, F. Um bocado de sexo, pouco giz, quase nada de apagador e muitas provas: cenas escolares envolvendo questões de gênero e sexualidade.

Revista Estudos Feministas, Florianópolis, v. 19, n. 2, p. 561-572, mai/ago. 2011.

SILVA, T. T. Documentos de identidade: uma introdução às teorias do currículo. $3^{\mathrm{a}}$ ed. $2^{\mathrm{a}}$ reimp. Belo Horizonte: Autêntica, 2011.

SOUZA, M. A. Entrevista ao Programa Correio em Debate em 30 de junho de 2015. TV Correio João Pessoa. Disponível em: <https://www. facebook.com/raonibmendes/videos/vb. $570693256352787 / 845934182162025 /$ ?type=2\&the ater>. Acesso em: 30 jul. 2015.

SOUZA, M. L. Carta à comunidade jequieense e vereadores. In: Comunidade da ONG LGBT Sol. Facebook. Publicada em 18 de junho de 2015. Disponível em: <https://www.facebook.com/ lgbtsoljequie/posts/480460495454823>. Acesso em: 30 jul. 2015. 
1 Mestre em Educação na linha de pesquisa Políticas Educacionais pelo Programa de Pós-Graduação em Educação da Universidade Federal da Paraíba. E-mail: jmartinscavalcante@gmail.com

2 Doutorando em Educação na linha de pesquisa Estudos Culturais da Educação pelo Programa de Pós-Graduação em Educação da Universidade Federal da Paraíba. E-mail: lukas_ro_mario@hotmail.com

3 Doutora em Currículo, Ensino e Política Educacional pela Michigan State University, USA (1997). Professora titular do Programa de Pós Graduação em Educação da Universidade Federal da Paraíba Núcleo Interdisciplinar de Pesquisa e Ação Sobre Mulher e a Relações de Sexo e Gênero (NIPAM/ UFPB). Bolsista de produtividade CNPq. E-mail: mepcarv@terra.com.br

4 Doutor em Sociologia (UFS). Professor do Programa de Pós-Graduação em Educação - PPGED da Universidade Federal da Sergipe. Pesquisador do Núcleo de Estudos e Pesquisas Interdisciplinares sobre a Mulher e Relações Sociais de Gênero (NEPIMG/UFS). E-mail: diasalfrancio@hotmail.com 
